\title{
Cervical Hibernoma: A Very Rare Tumor of Childhood - Case Report with Review of Literature
}

\begin{abstract}
Hibernomas are uncommon benign soft-tissue tumors which are composed of brown fat. They are usually seen in adults in the fourth and fifth decades and the common locations are thigh, shoulder, and back. Only few cases in the posterior neck region have been reported in literature. Hibernoma is very uncommon in the pediatric age group and those in the neck region are extremely rare. We present a hibernoma presenting as a swelling on the posterior aspect of base of the neck in a 5-month-old male infant. Considering the rare occurrence in the pediatric age group and difficulty in diagnosis, the clinical features, radiological features, pathological characteristics, differential diagnosis, and management of this rare tumor of childhood are discussed herewith.
\end{abstract}

Keywords: Brown fat tumor, cervical mass, hibernoma, pediatric neck mas

\section{Introduction}

Hibernomas are uncommon benign soft-tissue tumors, developed from fetal brown fat tissue, vestigial remnants of the evolution of the species. ${ }^{[1]}$ They are seen in the rare areas where brown fat remnants may persist, such as interscapular area, mediastinum, axilla, retroperitoneum, and neck. $^{[2,3]}$ Cervical hibernoma is very rare benign tumor that should be considered a differential diagnosis for posterior neck masses. It occurs mainly in adults and very few cases have been reported in children. ${ }^{[4,5]}$ The symptoms are compression of cervical structures, respiratory compromise, Horner's syndrome, and hemiparesis. ${ }^{[4]} \mathrm{We}$ hereby present a case of neck hibernoma in a 5-month-old male infant along with the review of clinical features and management of this extremely rare tumor in the pediatric age group.

\section{Case Report}

A 5-month-old male child presented with a history of a small swelling at the base of the nape of neck of 3-month duration. It gradually increased in size in the last 4 weeks before presentation. The infant had an uneventful birth history with normal developmental milestones. There was no history of trauma, discharge,

This is an open access journal, and articles are distributed under the terms of the Creative Commons Attribution-NonCommercial-ShareAlike 4.0 License, which allows others to remix, tweak, and build upon the work non-commercially, as long as appropriate credit is given and the new creations are licensed under the identical terms.

For reprints contact: WKHLRPMedknow_reprints@wolterskluwer.com or bleeding. The swelling caused some discomfort with movement, but there were no neurological deficits. The patient did not have difficulty in swallowing or breathing; his medical history was unremarkable. On examination, it was a nontender, soft, freely mobile swelling measuring $5 \mathrm{~cm} \times 4 \mathrm{~cm}$ with skin over the central part showing mild excoriation. Cough impulse and transillumination tests were negative. Various differential diagnoses that were considered were lipoma, lipoblastoma, hemangioma, encephalocele, and lymphangioma.

Laboratory evaluation showed hemoglobin of $11.2 \mathrm{~g} \%$ with normal total and differential leukocyte counts, erythrocyte sedimentation rate, and peripheral smear. Serum C-reactive protein was negative.

Ultrasound of the swelling revealed a heterogeneous mass at the base of posterior aspect of neck in midline with increased vascularity. On magnetic resonance imaging (MRI), a subcutaneous lesion was found superficial to the paravertebral muscles without any communication with the spinal cord. T1- and T2-weighted images showed increased peripheral vascularity. On T2 images, it was observed as a hypointense lesion [Figure 1].

The mass was excised completely, and the defect was repaired in layers.

How to cite this article: Prakash A, Singh S, Dhull K, Sharma S, Vyas T, Jain A. Cervical hibernoma: A very rare tumor of childhood - Case report with review of literature. Indian J Med Paediatr Oncol 2020;41:72-4.

\section{Advait Prakash', Sangram Singh ${ }^{1}$, Kshiteej Dhull', Sankalp Sharma ${ }^{2}$, Tanmay Vyas ${ }^{1}$, Anvesh Jain ${ }^{1}$}

${ }^{1}$ Department of Pediatric Surgery, Sri Aurobindo Institute of Medical Sciences and Post Graduate Institute, Indore, Madhya Pradesh, India, ${ }^{2}$ Department of General Surgery, Sri Aurobindo Institute of Medical Sciences and Post Graduate Institute, Indore, Madhya Pradesh, India

Submitted: 19-Mar-2018 Accepted in Revised Form: 21-Jun-2018

Published: 24-Apr-2020

Address for correspondence: Dr. Advait Prakash, Department of Pediatric Surgery, Sri Aurobindo Institute of Medical Sciences and Post Graduate Institute, Indore, Madhya Pradesh, India. E-mail:drprakashadvait@ rediffmail.com

Access this article online

Website: www.ijmpo.org

DOI: 10.4103/ijmpo.ijmpo_63_18 Quick Response Code:

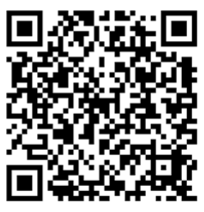




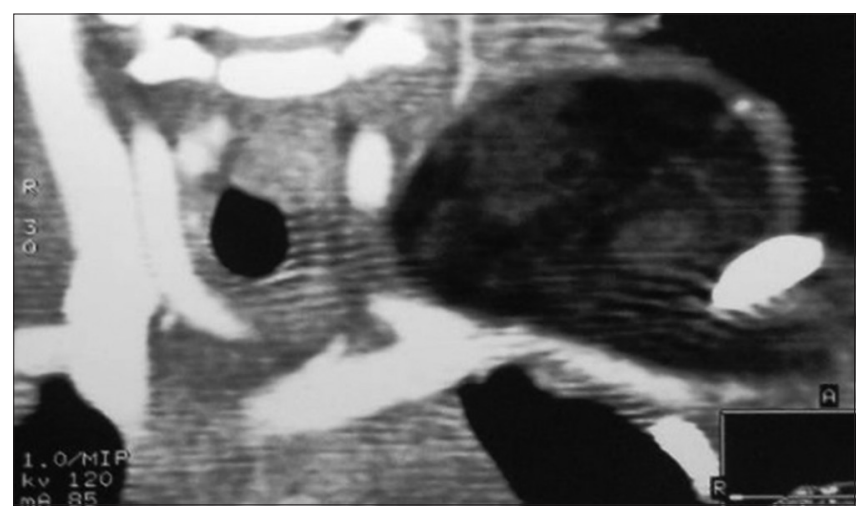

Figure 1: Magnetic resonance imaging showing posterior cervical lesion

Histopathological evaluation (HPE) confirmed the diagnosis of benign hibernoma. HPE showed the tumor to have a thick intact capsule consisting of collagenous connective tissue. On microscopy, abundant brown fat with a plenty of fat lobules separated by connective tissue septa was present. This was depicted by cells with granular deeply eosinophilic cytoplasm along with clear multivacuolated cells filled with lipid droplets [Figure $2 \mathrm{a}$ and $\mathrm{b}$ ]. The nuclei were small, regular, and round with no atypia and rare mitoses. Postoperative recovery was uneventful, and the patient was discharged on the $3^{\text {rd }}$ postoperative day. There was no recurrence after 1 year of follow up.

\section{Discussion}

Hibernoma is a rare benign soft-tissue tumor composed of multiloculated fat cells derived from brown fat. This tumor was first described in 1906 by Merkl. The term hibernoma was coined in 1914 by Gery because of the morphologic similarity of the tumor to the brown fat cells of the hibernating mammals. ${ }^{[6,7]}$ Brown adipose tissue exists in humans in intrauterine life and may be recognized after the $21^{\text {st }}$ week of gestation. Brown fat is found physiologically in newborns in the axilla and the subpleural regions, but it usually disappears after 8 weeks of life. ${ }^{[7]}$ As maturation proceeds, it is slowly replaced by white fat. It may persist in certain areas such as neck, axilla, periaortic area, mediastinum, and perirenal areas. ${ }^{[8]}$ The function of this brown fat is to promote nonshivering thermogenesis. ${ }^{[1]}$ On thorough literature search, we found that $<20$ cases of cervical hibernoma have been reported till date. Majority of cases are among adult patients and cervical hibernoma in children is extremely rare.

Hibernomas are mostly seen in the fourth and fifth decades of life, and previously, a female predominance was reported with a mean age of 38 years. ${ }^{[5-7]}$ Clinically, their consistency is multiple but usually harder than a regular lipoma. It is a mobile, slow-growing mass. It is usually asymptomatic but rarely may present with pain weight loss. ${ }^{[9,10]}$ Most common anatomical locations were the thigh shoulder, back, neck, chest, arm, and abdominal cavity. ${ }^{[8]}$

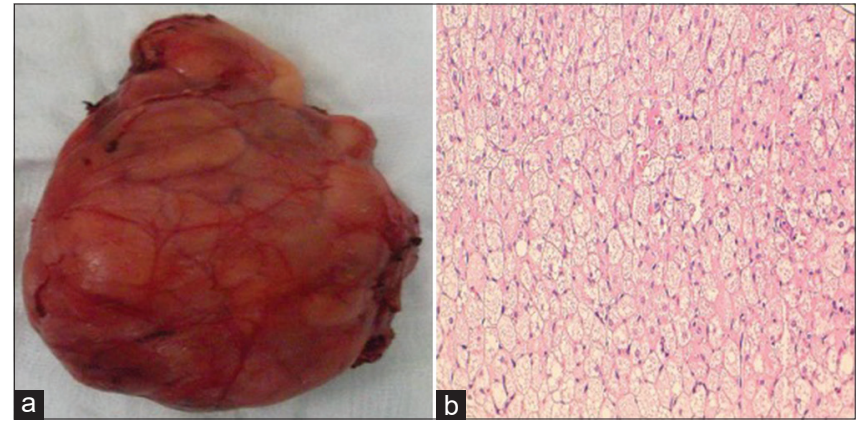

Figure 2: (a) Gross specimen after complete excision, (b) microscopic histopathological evaluation of the excised specimen

Diagnostic imaging studies are invaluable in the preliminary diagnosis of fatty tumors. ${ }^{[2]}$ Plain X-rays and computed tomography (CT) scan can suggest the fat density of the tumor. Results of ultrasonography examinations can be confusing. The MRI is the most reliable method showing location, size, extent, and mass characteristics of the tumor. ${ }^{[1]}$ Hibernomas are usually depicted as heterogeneous masses with marked contrast enhancement. The CT and MRI examinations show a well-demarcated mass having signal intensity which is intermediate between subcutaneous fat and muscle. The lesion enhances after contrast injection. Despite presenting as brown fat, the T1- and T2-weighted images demonstrate high-signal intensity but slightly less than that of the subcutaneous fat. On fat-suppression sequences, there may be incomplete fat suppression because of the nature and amount of lipids. ${ }^{[6,7,11]}$

The needle biopsy carries a risk of hemorrhage and often leads to inconclusive results; hence, the definitive diagnosis is based on histopathological analysis after surgical excision biopsy. ${ }^{[6]}$ The microscopic examination of the tumor is characterized by cells of various degrees of differentiation. Usually, multivacuolar adipocytes and brown fat cells with granular eosinophilic cytoplasm are interspersed with univacuolar adipocytes. ${ }^{[1]}$ The characteristic color of hibernoma is derived from the increased vascularity combined with abundant mitochondria. ${ }^{[1]}$ Four histological variants of hibernoma have been described by Furlong et al. [Table 1]. ${ }^{[5]}$

Recent studies have suggested that formation of hibernoma may have an underlying genetic predisposition. It has been found that these tumors present with a balanced translocation between 11q13 chromosome and other chromosomes. These translocations have been associated with MENI and AIP genes. ${ }^{[12]}$

The differential diagnosis of any lipomatous tumor should include lipoma, lipoblastoma, hibernoma, and liposarcoma, all of which can be differentiated on detailed HPE. ${ }^{[13]}$ The lipoma is the most common soft-tissue tumor and may show cytologic similarities to lipoblastoma. Both of them differ by the fact that the extent of vacuolated adipocytes is greater in number and smaller in lipoblastoma in contrast to lipoma. ${ }^{[14]}$ 


\begin{tabular}{ll}
\hline $\begin{array}{c}\text { Table 1: Classification and histopathological characters } \\
\text { of various types of hibernoma }\end{array}$ \\
\hline Histological type & Characteristic features \\
\hline Typical hibernoma & Eosinophilic, pale cell and mixed cell types \\
Myxoid variant & Loose basophilic matrix \\
Spindle cell & Features of hibernoma and spindle cell \\
hibernoma & lipoma \\
Lipoma-like variant & Scattered hibernoma cell \\
\hline
\end{tabular}

Hibernomas differ from others in having a central nucleus and abundant finely granular or microvacuolated cytoplasm. In addition, smears show the absence of myxoid matrix and paucity of capillaries. ${ }^{[14]}$ Furthermore, hibernoma shows a lobular pattern which is entirely composed of brown fat with eosinophilic granular cytoplasm in contrast to the white fat seen in other adipose tumors. ${ }^{[13]}$ Liposarcoma is different from lipoblastoma on histology. It is important to recognize that both tumors may contain mitotic figures and plexiform capillary network but these are more prominent in myxoid liposarcoma. Hyperchromasia and nuclear atypia which may be the most distinguishing features are observed typically in liposarcoma but absent in lipoblastoma. On the other hand, the characteristic lobulation of lipoblastoma is usually not seen in liposarcoma, except in the myxoid variant on rare instances. ${ }^{[13]}$

The treatment of choice for hibernoma is complete excision with preservation of vital structures. ${ }^{[4,10]}$ Hibernoma usually present as a well-circumscribed lesion; hence, the complete excision of the lesion is not a problem. Unlike lipomas, the hibernomas have an extensive vascularity that should be carefully treated to avoid postoperative bleeding or hematoma. No recurrence or metastasis has been reported. ${ }^{[4,10]}$

\section{Conclusion}

Hibernoma is a rare benign soft-tissue tumor which arises from brown adipose tissue. It is very uncommon in the cervical region and is extremely rare in the pediatric age group. Their rarity and lack of awareness make their diagnosis clinically challenging. The curative treatment is a complete excision. All neck masses excised should be subjected for HPE for adequate treatment.

\section{Declaration of patient consent}

The authors certify that they have obtained all appropriate patient consent forms. In the form the patient(s) has/have given his/her/their consent for his/her/their images and other clinical information to be reported in the journal. The patients understand that their names and initials will not be published and due efforts will be made to conceal their identity, but anonymity cannot be guaranteed.

\section{Acknowledgment}

We would like to acknowledge the help offered by following individuals in preparation of this article (i) Dr. Milind Joshi, Associate Professor, Department of Pediatric Surgery, Sri Aurobindo Institute of Medical Sciences and Post Graduate Institute, Indore, Madhya Pradesh. (ii) Dr. Amit Verma, Professor and Head, Departmentof Pathology, Sri Aurobindo Institute of Medical Sciences and Post Graduate Institute, Indore, Madhya Pradesh.

\section{Financial support and sponsorship}

Nil.

\section{Conflicts of interest}

There are no conflicts of interest.

\section{References}

1. Khattala K, Elmadi A, Bouamama H, Rami M, Bouabdallah Y. Cervical hibernoma in a two year old boy. Pan Afr Med J 2013;16:27.

2. Grayson JW, Wallace JC. A case report and discussion of hibenomas: Pathology, genetics, diagnosis and treatment. Am J Clin Med 2012;9:151-3.

3. Minni A, Barbaro M, Vitolo D, Filipo R. Hibernoma of the para-glottic space: An unusual tumour of the larynx. Acta Otorhinolaryngol Ital 2008;28:141-3.

4. Nardi CE, Barreto L, Carvalho LV, Guimarães AV. Cervical hibernoma and lipoblastomatosis. Einstein (Sao Paulo) 2013;11:111-3

5. Furlong MA, Fanburg-Smith JC, Miettinen M. The morphologic spectrum of hibernoma: A clinicopathologic study of 170 cases. Am J Surg Pathol 2001;25:809-14.

6. Hertoghs M, Van Schil P, Rutsaert R, Van Marck E, Vallaeys J. Intrathoracic hibernoma: Report of two cases. Lung Cancer 2009;64:367-70.

7. Della Volpe C, Salazard B, Casanova D, Vacheret H, Bartoli JF, Magalon $\mathrm{G}$, et al. Hibernoma of the antero-lateral thigh. Br J Plast Surg 2005;58:859-61.

8. Samayam P, Ramesh AC, Chandra NS, Patil MR, Prasanna DH. Hibernoma at base of neck - A rare case in a six month old infant. IJMPCR 2015;4:121-4.

9. Boudana D, Wolber A, De Lesalle EM, Delaporte E, Martinot-Duquennoy V. Hibernoma: An uncommon adipocytic tumor. Ann Chir Plast Esthet 2011;56:156-9.

10. Peycru T, Tardat E, Schwartz A, Dufau JP, Benois A, Durand-Dastes F, et al. Hibernoma of the neck: A rare benign tumour. Can J Surg 2009;52:E52-3.

11. da Motta AC, Tunkel DE, Westra WH, Yousem DM. Imaging findings of a hibernoma of the neck. AJNR Am J Neuroradiol 2006;27:1658-9.

12. Nord KH, Magnusson L, Isaksson M, Nilsson J, Lilljebjörn H, Domanski HA, et al. Concomitant deletions of tumor suppressor genes MEN1 and AIP are essential for the pathogenesis of the brown fat tumor hibernoma. Proc Natl Acad Sci U S A 2010;107:21122-7.

13. Brodsky JR, Kim DY, Jiang Z. Cervical lipoblastoma: Case report, review of literature, and genetic analysis. Head Neck 2007;29:1055-60.

14. López-Ferrer P, Jiménez-Heffernan JA, Yébenes L, Vicandi B, Viguer JM. Fine-needle aspiration cytology of lipoblastoma: A report of two cases. Diagn Cytopathol 2005;32:32-4. 